\title{
Níveis de lisina digestível para suínos machos castrados de alto potencial genético dos 95 aos $125 \mathrm{~kg}^{1}$
}

\author{
Fabrício de Almeida Santos ${ }^{2}$, Juarez Lopes Donzele ${ }^{3}$, Francisco Carlos de Oliveira Silva ${ }^{4}$, \\ Rita Flávia Miranda de Oliveira ${ }^{3}$, Márvio Lobão Teixeira de Abreu ${ }^{5}$, Alysson Saraiva ${ }^{6}$, \\ Douglas Haese ${ }^{7}$, Anderson Lazarini Lima ${ }^{6}$
}

\author{
1 Financiado pelo CNPq e apoiado pela Ajinomoto. \\ 2 Agroceres Nutrição Animal. \\ 3 DZO/UFV. \\ ${ }^{4}$ EPAMIG. \\ ${ }^{5}$ DZO/UFPI. \\ ${ }^{6}$ Estudante de Doutorado DZO/UFV. \\ ${ }^{7}$ DZO/UVV
}

RESUMO - Avaliou-se o efeito de níveis de lisina digestível sobre o desempenho e a composição de carcaça de suínos machos castrados de alto potencial genético para deposição de carne. Foram utilizados 80 animais com peso inicial de $95,55 \pm 1,04$ distribuídos em delineamento experimental de blocos ao acaso, com cinco dietas $(0,540 ; 0,642 ; 0,744 ; 0,846$ e $0,948 \%$ de lisina digestível), oito repetições e dois animais por unidade experimental. As dietas experimentais e água foram fornecidas à vontade durante todo o período experimental. Os níveis de lisina digestível não influenciaram o consumo de ração diário e o peso de carcaça dos animais. O ganho de peso diário e a conversão alimentar melhoraram de forma quadrática até os níveis de lisina digestível estimados de 0,803 e $0,817 \%$, respectivamente. Foi observado efeito linear crescente dos tratamentos sobre o consumo diário de lisina e sobre a quantidade de carne. Embora, a deposição diária de carne tenha aumentado de forma linear, o modelo LRP foi o que melhor se ajustou aos dados que permaneceram em um platô a partir do nível de lisina digestível de $0,803 \%$. Os níveis de lisina digestível influenciaram a espessura de toucinho $\mathrm{P}_{2}$ dos animais que reduziu de forma linear. O nível de lisina digestível de 0,803\%, que corresponde a consumo de 24,60 g/dia de lisina digestível, proporciona os melhores resultados de ganho de peso e deposição de carne, enquanto o nível de 0,817\%, correspondente a consumo de 25,03 g/dia de lisina, proporciona melhor conversão alimentar e o de 0,948\%, correspondente a consumo de 29,09 g/dia de lisina digestível, promove maior deposição de carne e espessura de toucinho em suínos machos castrados na fase dos 95 aos $125 \mathrm{~kg}$.

Palavras-chaves: aminoácido digestível, carcaça, desempenho, terminação tardia

\section{Digestible lysine levels for barrows with high genetic potencial from 95 to $125 \mathrm{~kg}$}

\begin{abstract}
This work evaluated levels of digestible lysine on performance and carcass composition of barrows with high genetic potential for meat deposition. It was used 80 animals with initial body weight of $95.55 \pm 1.04 \mathrm{~kg}$, distributed in a completely randomized block design, with 5 diets (0.540; 0.642; 0.744; 0.846 and $0.948 \%$ of digestible lysine), eight replicates and two animals per experimental unit. The experimental diets and water were provided ad libitum throughout the experimental period. Digestible lysine levels did not change daily feed intake and carcass weight of the animals. Daily weight gain and feed conversion improved in a quadratic way up to the estimated levels of 0.803 and $0.871 \%$ of digestible lysine, respectively. It was observed an increasing linear effect of the treatments on daily lysine intake and amount of meat. Although daily meat deposition had increased in a linear way, the LRP was the model that best adjusted to the data which remained on a plateau from $0.803 \%$ of digestible lysine level. The levels of digestible lysine influenced the $\mathrm{P}_{2}$ backfat thickness of the animals which decreased in a linear way. The digestible lysine level of $0.803 \%$, corresponding to an intake of $24.60 \mathrm{~g} /$ day of digestible lysine provides the best results of weight gain and meat deposition whereas the level of $0.817 \%$ corresponding to an intake of $25.30 \mathrm{~g} /$ day of lysine provides the best result of feed conversion, and the digestible lysine level of $0.948 \%$ corresponding to an intake of $29.09 \mathrm{~g} /$ day of digestible lysine provides the best results of meat deposition and backfat thickness of barrows from 95 to $125 \mathrm{~kg}$.
\end{abstract}

Key Words: digestible amino acids, carcass, late finishing, performance 


\section{Introdução}

O avanço da suinocultura nacional, principalmente nas áreas de nutrição e melhoramento genético, tem permitido o abate de animais com peso superior a $95 \mathrm{~kg}$. O processamento de carcaças mais pesadas possibilita aos frigoríficos aperfeiçoar o uso de mão-de-obra e equipamentos e produzir maior quantidade de produtos com menores custos fixos por animal processado. $\mathrm{O}$ abate de animais com $120 \mathrm{~kg}$, representa um rendimento de carcaça de $75 \%$ e de carne acima de 55\%, otimizando a produção nos frigoríficos (Faccin, 1997).

As linhagens comerciais contemporâneas apresentam alto potencial genético para deposição de carne magra na carcaça possibilitando abates tardios. Porém, suínos com alto potencial genético para deposição de carne na carcaça exigem maiores quantidades diárias de lisina para máximos desempenho e deposição protéica (Stahly et al., 1991; Friesen et al., 1994a, 1995).

A lisina é o primeiro aminoácido limitante em dietas à base de milho e soja para suínos (NRC,1998) e diretamente responsável pela deposição de tecido muscular na carcaça, portanto, as respostas de desempenho e deposição de carne magra na carcaça podem estar associadas ao seu nível na dieta (Oliveira et al., 2003b).

Tem-se constatado que as informações disponíveis na literatura relacionadas à exigência de lisina para suínos pesados são inconsistentes, sendo que as recomendações variam entre $0,62 \%$ de lisina total para suínos dos 96 aos $120 \mathrm{~kg}$ (Arouca et al., 2005); 0,72\% de lisina total para suínos dos 95 aos $122 \mathrm{~kg}$ (Arouca et al., 2004) e 0,80\% de lisina total para suínos dos 110 aos $125 \mathrm{~kg}$ (Oliveira et al., 2003b). Por sua vez, a recomendação preconizada pelas tabelas brasileiras de exigências nutricionais (Rostagno et al., 2005) é de $0,75 \%$ de lisina digestível para suínos dos 100 aos 120 kg. Diante da constante evolução genética a reavaliação das exigências nutricionais, em especial da lisina digestível, se faz necessária, uma vez que os suínos apresentam seu desempenho e características de carcaça melhoradas e, por conseqüência, podem ter suas exigências aminoacídicas aumentadas. Nesse sentido, conduziu-se este trabalho com o objetivo de avaliar níveis de lisina digestível nas dietas sobre o desempenho e as características de carcaça de suínos machos castrados de alto potencial genético dos 95 aos $125 \mathrm{~kg}$.

\section{Material e Métodos}

O experimento foi realizado na Granja de Suínos da Fazenda Experimental Vale do Piranga da EPAMIG, localizada no município de Oratórios, Minas Gerais, no período de janeiro a abril de 2005.

Foram utilizados 80 suínos machos castrados, híbridos comerciais PIC com alto potencial genético para deposição de carne, na fase dos 95 aos 125 kg, distribuídos em delineamento experimental de blocos ao acaso, com cinco dietas, com oito repetições e dois animais por baia. A unidade experimental foi representada pela baia. Na distribuição dos animais dentro de cada bloco, adotou-se como critério o peso inicial.

As dietas experimentais, isoproteícas e isoenergéticas (Tabela 1), foram formuladas à base de milho, farelo de soja e glúten de milho e suplementadas com minerais e vitaminas, conforme recomendações nutricionais descritas por Rostagno et al. (2000). As dietas corresponderam a 0,$540 ; 0,642 ; 0,744 ; 0,846$ e 0,948\% de lisina digestível, obtidos a partir de uma dieta basal suplementada com L-lisina HCl. Em cada nível de lisina estudado, foi verificada a relação entre os demais aminoácidos essenciais e a lisina digestível, a fim de assegurar que nenhum aminoácido ficasse limitante na dieta, exceto a lisina. Na avaliação das relações aminoacídicas das dietas, foram utilizadas as relações preconizadas por Fuller (1996) na proteína ideal para suínos de 50 a 110 kg. Aminoácidos industriais foram adicionados às dietas em substituição ao ácido glutâmico, com base no equivalente protéico, e o total foi ajustado para $100 \mathrm{~kg}$ nas dietas, por meio do inerte.

Os animais foram alojados em baias providas de comedouro semi-automático e bebedouros tipo chupeta, localizadas em um galpão de alvenaria com piso de concreto coberto com telhas de amianto.

Durante o período experimental, os animais receberam as dietas experimentais e água à vontade. As sobras das dietas eram coletadas diariamente e armazenadas em sacos plásticos localizados à frente de cada unidade experimental. Semanalmente, as sobras das dietas e os animais foram pesados para determinação do ganho de peso, do consumo de ração e da conversão alimentar.

A temperatura do ar foi registrada diariamente por meio de um termômetro de máxima e mínima, colocado no interior do galpão.

Ao final do período experimental, quando atingiram o peso final de 125,06 $\pm 2,90 \mathrm{~kg}$, os animais foram mantidos em jejum por 18 horas e, em seguida, foram pesados e encaminhados para o abate, realizado em um Frigorífico Industrial do Vale do Piranga, localizado na cidade de Ponte Nova, no estado de Minas Gerais - Brasil. Os animais foram insensibilizados por choque elétrico e sacrificados por sangramento. 
Tabela 1 - Composição centesimal e calculada das dietas experimentais

\begin{tabular}{|c|c|c|c|c|c|}
\hline Ingrediente & \multicolumn{5}{|c|}{ Nível de lisina digestível (\%) } \\
\hline Milho & 75,990 & 75,990 & 75,990 & 75,990 & 75,990 \\
\hline Glúten de milho & 3,400 & 3,400 & 3,400 & 3,400 & 3,400 \\
\hline Óleo de soja & 1,200 & 1,200 & 1,200 & 1,200 & 1,200 \\
\hline Fosfato bicálcico & 1,275 & 1,275 & 1,275 & 1,275 & 1,275 \\
\hline Inerte & 0,100 & 0,183 & 0,286 & 0,392 & 0,518 \\
\hline L-lisina $\mathrm{HCl}(78,5 \%)$ & - & 0,130 & 0,260 & 0,390 & 0,520 \\
\hline DL-metionina (99\%) & - & - & 0,014 & 0,087 & 0,151 \\
\hline L-treonina $(98,5 \%)$ & - & - & 0,060 & 0,141 & 0,220 \\
\hline L-triptofano $(99 \%)$ & - & 0,009 & 0,033 & 0,053 & 0,075 \\
\hline L-valina $(99 \%)$ & - & - & - & - & 0,045 \\
\hline Bacitracina de zinco & 0,020 & 0,020 & 0,020 & 0,020 & 0,020 \\
\hline $\mathrm{BHT}^{3}$ & 0,010 & 0,010 & 0,010 & 0,010 & 0,010 \\
\hline \multicolumn{6}{|c|}{ Níveis nutricionais calculados ${ }^{4} /$ estimados $^{5}$} \\
\hline Proteína bruta (\%) & 15,9 & 15,9 & 15,9 & 15,9 & 15,9 \\
\hline Energia digestível (kcal/kg) & 3.400 & 3.400 & 3.400 & 3.400 & 3.400 \\
\hline Lisina total $(\%)$ & $0,605 / 0,631$ & $0,707 / 0,733$ & $0,808 / 0,835$ & $0,910 / 0,937$ & $1,012 / 1,039$ \\
\hline Lisina digestível (\%) & $0,550 / 0,540$ & $0,651 / 0,642$ & $0,750 / 0,744$ & $0,850 / 0,846$ & $0,950 / 0,948$ \\
\hline Metionina + cistina digestível (\%) & $0,500 / 0,488$ & $0,500 / 0,488$ & $0,514 / 0,502$ & $0,586 / 0,574$ & $0,648 / 0,637$ \\
\hline Treonina digestível (\%) & $0,489 / 0,502$ & $0,489 / 0,502$ & $0,544 / 0,561$ & $0,617 / 0,641$ & $0,689 / 0,718$ \\
\hline Triptofano digestível $(\%)^{4}$ & 0,131 & 0,139 & 0,162 & 0,180 & 0,201 \\
\hline Isoleucina digestível (\%) & $0,546 / 0,562$ & $0,546 / 0,562$ & $0,546 / 0,562$ & $0,546 / 0,562$ & $0,612 / 0,628$ \\
\hline Valina digestível (\%) & $0,623 / 0,669$ & $0,623 / 0,669$ & $0,623 / 0,669$ & $0,623 / 0,669$ & $0,668 / 0,713$ \\
\hline
\end{tabular}

As carcaças foram depiladas com lança-chamas, evisceradas e pesadas e, posteriormente, foram avaliadas à espessura de toucinho no ponto $\mathrm{P}_{2}$ e quantidade de carne, por meio de aparelho de tipificação de carcaça com pistola Henessay Grading Probe (HGP-4). Os dados de espessura de toucinho e quantidade de carne na carcaça foram obtidos imediatamente após o abate, na banda esquerda de cada carcaça, no ponto $\mathrm{P}_{2}$, correspondente à projeção perpendicular da última costela sobre o músculo longíssimo dorsal a quatro $\mathrm{cm}$ da coluna vertebral seguindo os procedimentos adotados pelo frigorífico.

A deposição diária de carne (DDC) foi estimada utilizando-se os dados de peso inicial dos animais (PI), rendimento de carcaça (RC), peso de carcaça estimado (PCE), porcentagem de carne na carcaça (PC), quantidade de carne final (QCF), quantidade de carne inicial estimada (QCIE) e dias no período experimental (D).

Os valores de rendimento de carcaça e porcentagem de carne na carcaça foram obtidos utilizando-se os resultados de carcaça de Rossoni et al. (2008), que avaliaram suínos machos castrados dos 60 aos $95 \mathrm{~kg}$. Neste trabalho, os animais foram abatidos aos $95 \mathrm{~kg}$ e o rendimento de carcaça foi obtido pelo Método Brasileiro de Classificação de Carcaça (CCMB) (Associação..., 1973), considerando a relação entre o peso da carcaça quente e o peso vivo final dos animais, enquanto a porcentagem de carne na carcaça foi determinada segundo metodologia utilizada no Frigorífico Industrial do Vale do Piranga.

A PCE, QCIE, QCE e a DDC foram determinadas por meio de equações propostas por Fowler et al. (1976), em que: $\mathrm{PCE}=(\mathrm{PI} \times \mathrm{RC}) / 100$; $\mathrm{QCIE}=(\mathrm{PCE} \times \mathrm{PC}) / 100$; $\mathrm{QCE}=\mathrm{QCF}-\mathrm{QCIE}$;

$\mathrm{DDC}(\mathrm{g} / \mathrm{dia})=(\mathrm{QCE} / \mathrm{D}) \times 1000$.

Foram avaliados o consumo diário de ração, o ganho de peso diário, o consumo diário de lisina digestível, a conversão alimentar, a espessura de toucinho no ponto $\mathrm{P}_{2}$, a quantidade de carne, o peso da carcaça e a deposição diária de carne. 
As análises estatísticas das características de desempenho e carcaça foram realizadas utilizando o programa SAEG (2000). As estimativas dos níveis de lisina digestível foram determinadas por meio de análises de regressão linear, quadrática e/ou pelo modelo descontínuo "Linear Response Plateau” (LRP), conforme o melhor ajustamento obtido para cada variável estudada.

\section{Resultados e Discussão}

As temperaturas registradas no termômetro de mínima e máxima durante o período experimental foram, respectivamente, $22,14 \pm 1,5^{\circ} \mathrm{C}$ e $29,09 \pm 2,5^{\circ} \mathrm{C}$. Considerando que a temperatura crítica superior para suínos na fase de terminação é de $27^{\circ} \mathrm{C}$ (Leal \& Nããs, 1992), constatou-se com base na variação das temperaturas mínima e máxima apresentadas durante o período experimental que os animais podem ter sido submetidos a estresse por calor.

Não foram observados efeitos dos níveis de lisina $(\mathrm{P}>0,05)$ sobre o consumo diário de ração (Tabela 2). Resultados semelhantes foram obtidos por vários pesquisadores (Friesen et al., 1994b, 1995; Hanh et al., 1995; Dourmad et al., 1996; Loughmiller et al., 1998; Cline et al., 2000 e Arouca et al., 2004, 2005), com suínos em fase de terminação tardia. Segundo Edmonds \& Baker (1987), os suínos conseguem tolerar excessos de aminoácidos nas dietas, principalmente lisina, sem apresentar variações significativas no consumo alimentar.

A redução no consumo de alimentos pode ser uma das características de dietas com desbalanço de aminoácidos (Henry, 1985 e D’Mello, 1993). Neste estudo, o desbalanço de aminoácidos foi evitado pela suplementação das dietas com aminoácidos sintéticos (DL-metionina, L-treonina, L-triptofano, L-valina e L-isoleucina), à medida que os níveis de lisina da dieta foram aumentados para manutenção da relação entre os aminoácidos e a lisina.

O consumo médio diário de ração (3.057 g/dia) observado neste estudo foi inferior aos registrados por Oliveira et al. (2003a), que verificaram consumo de 3.180 g/dia sob temperaturas mínima e máxima, respectivamente, de
$17,1 \pm 4,94^{\circ} \mathrm{C}$ e $24,1 \pm 4,01^{\circ} \mathrm{C}$ e por Arouca et al. (2004), que constataram consumo de $3.433 \mathrm{~g} / \mathrm{dia}$, com temperaturas mínima e máxima, respectivamente, de $12,98 \pm 2,37^{\circ} \mathrm{C}$ e $27,75 \pm 3,26^{\circ} \mathrm{C}$.

Com base nessas observações, pode-se inferir que as altas temperaturas registradas neste trabalho influenciaram o consumo diário de ração pelos animais. De acordo com Quiniou et al. (2000), suínos quando expostos à alta temperatura ambiental apresentam capacidade limitada em dissipar calor para o ambiente, o que torna a redução da ingestão de alimentos um dos mecanismos utilizados para diminuir a produção de calor.

O consumo diário de lisina digestível aumentou $(\mathrm{P}<0,01)$ de forma linear, de acordo com os níveis desse aminoácido na ração, e pode ser representado pela equação: $\hat{Y}=-0,2788$ $+30,977 \mathrm{X}\left(\mathrm{r}^{2}=0,98\right)$. Aumento linear no consumo diário de lisina digestível por suínos em fase de terminação tardia, atribuído à sua concentração na dieta, também foi relatado por Loughmiller et al. (1998), Bertol et al. (2000), Cline et al. (2000), Oliveira et al. (2003a, b) e Arouca et al. (2005).

Uma vez que o consumo diário das dietas não variou $(\mathrm{P}>0,05)$ entre os níveis de lisina digestível na dieta, o aumento no consumo diário de lisina digestível pode ser atribuído ao nível crescente de lisina na dieta.

Neste estudo, verificou-se efeito $(\mathrm{P}<0,05)$ dos níveis de lisina digestível sobre o ganho de peso diário dos animais, que aumentou de forma quadrática até o nível estimado de 0,803\% (Figura 1 ), que corresponde a um consumo de lisina digestível de 24,60 g/dia.

Resultados semelhantes foram observados por Arouca et al. (2005), em suínos machos castrados selecionados geneticamente para eficiência de crescimento dos 96 aos $120 \mathrm{~kg}$. Esses autores observaram consumo total de lisina de 27,84 g/dia, correspondente ao consumo de lisina digestível de 24,78 g/dia. Outros pesquisadores (Loughmiller et al., 1998; Witte et al., 2000; Oliveira et al., 2003a, b), no entanto, não observaram efeito significativo dos níveis de lisina da dieta sobre o ganho de peso diário de suínos em fase de terminação tardia. Bertol et al. (2000), trabalhando com suínos machos castrados de 80 a 120 kg,

Tabela 2 - Desempenho de suínos machos castrados dos 95 aos 125 kg, em função dos níveis de lisina digestível nas dietas

\begin{tabular}{lcccccc}
\hline Variável & \multicolumn{3}{c}{ Níveis de lisina digestível (\%) } \\
\cline { 2 - 4 } & 0,540 & 0,642 & 0,744 & 0,846 & 0,948 \\
\hline Consumo diário de ração(g) & 2.939 & 3.208 & 2.991 & 3.099 & 3.046 \\
Consumo diário de lisina digestível $(\mathrm{g})^{1}$ & 15,87 & 20,60 & 22,25 & 26,22 & 28,88 & 6,98 \\
Ganho de peso diário (g) & 937 & 1.047 & 1.099 & 1.086 & 1.058 & 8,97 \\
Conversão alimentar (g/g) & 3,14 & 3,06 & 2,72 & 2,85 & 2,90 \\
\hline
\end{tabular}

${ }^{1}$ Efeito linear $(\mathrm{P}<0,01)$.

2 Efeito quadrático $(\mathrm{P}<0,05)$

${ }^{3}$ Efeito quadrático $(\mathrm{P}<0,01)$. 

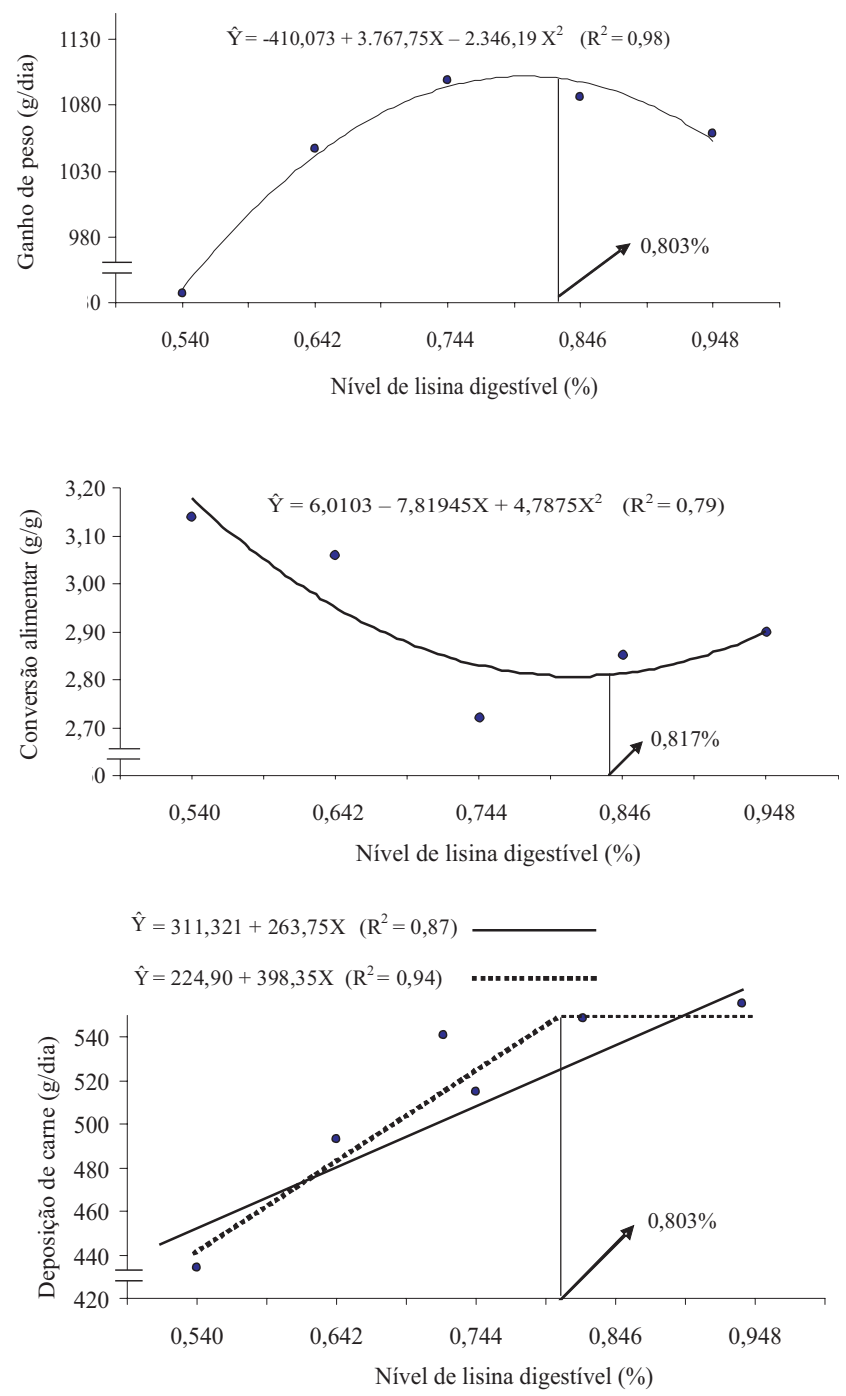

Figura 1 - Ganho de peso, conversão alimentar e deposição de carne em suínos machos castrados dos 95 aos $125 \mathrm{~kg}$ em função dos níveis de lisina digestível da dieta.

verificaram decréscimo linear do ganho de peso dos animais quando os níveis de lisina digestível da dieta aumentaram de 0,60 para $0,90 \%$.

O ganho de peso diário proporcionado pelo nível de 0,803\% de lisina digestível foi de 1.102,6 g/dia, próximo ao obtido por Arouca et al. (2004), de 1.099,12 g/dia, para um nível de $0,73 \%$ de lisina total. Todavia, foi superior ao proposto por Rostagno et al. (2005), de $980 \mathrm{~g} / \mathrm{dia}$, para um nível de $0,66 \%$ de lisina digestível para suínos em fase de terminação tardia (100 aos $120 \mathrm{~kg}$ ). A diferença de ganho de peso diário entre esses trabalhos pode estar relacionada aos grupos genéticos utilizados, ao sistema de alimentação (Stahly et al., 1991), ao perfil de aminoácidos da dieta, ao estado de saúde e ao sexo dos animais e ao ambiente.
Considerando os resultados de ganho de peso diário dos animais neste estudo, pode-se inferir que suínos machos castrados com alto potencial para deposição de carne na carcaça respondem aos níveis de lisina da dieta até o ponto determinado pelo potencial do genótipo.

A conversão alimentar dos animais foi influenciada pelos níveis de lisina das dietas e melhorou $(\mathrm{P}<0,01)$ de forma quadrática até o nível estimado de 0,817\% de lisina digestível, correspondente a um consumo de lisina digestível estimado de 25,03 g/dia (Figura 1).

Efeito positivo dos níveis de lisina da dieta sobre a eficiência de utilização do alimento para ganho de peso foi observado por Loughmiller et al. (1998), King et al. (2000), Witte et al. (2000) e Oliveira et al. (2003b) em suínos na fase de terminação tardia. No entanto, Johnston (1993), em experimento com suínos dos 105 aos 127 kg, e De la Llata et al. (2002), com suínos dos 90 aos 120 kg, não observaram efeito positivo dos níveis de lisina sobre a eficiência de utilização do alimento para ganho de peso dos suínos.

A variação na conversão alimentar entre os estudos pode ser atribuída ao nível de lisina utilizada nas dietas experimentais, ao sexo e ao potencial genético dos animais. De acordo com Stahly (1993), animais de alto potencial genético são mais eficientes na utilização do alimento para deposição de carne e respondem de forma positiva ao aumento no nível de lisina das dietas em comparação a animais de baixo potencial genético para deposição de carne, que apresentam menor eficiência de utilização do alimento para deposição muscular.

Os níveis de lisina digestível de 0,803 e 0,817\% obtidos neste trabalho, para melhores resultados de ganho de peso diário e conversão alimentar, respectivamente, foram superiores aos de 0,$72 ; 0,61 ; 0,76$ e $0,80 \%$ de lisina total, obtidos, respectivamente, por Arouca et al. (2004; 2005) e Oliveira et al. (2003a,b). Considerando esses resultados, provavelmente os níveis de lisina digestível de 0,60 e $0,75 \%$, preconizados, respectivamente, pelo NRC (1998) e por Rostagno et al. (2005) para suínos de 100 a 120 kg, não atendem às exigências das linhagens comerciais atuais, com maior eficiência de ganho em carne na carcaça.

Não foi observado efeito $(\mathrm{P}>0,05)$ dos níveis de lisina digestível sobre o peso da carcaça (Tabela 3). Resultados semelhantes foram observados por Friesen et al. (1995), Souza Filho et al. (2000), Kill et al. (2003), Oliveira et al. (2003 a,b) e Arouca et al. (2004; 2005). Gonçalves et al. (1999), no entanto, em experimento com machos castrados e fêmeas dos 60 aos $112 \mathrm{~kg}$, observaram aumento significativo no 
Tabela 3 - Características de carcaças de suínos machos castrados dos 95 aos 125 kg, em função dos níveis de lisina digestível na ração

\begin{tabular}{|c|c|c|c|c|c|c|}
\hline \multirow[t]{2}{*}{ Variável } & \multicolumn{5}{|c|}{ Níveis de lisina digestível (\%) } & \multirow{2}{*}{$\begin{array}{l}\text { CV } \\
(\%)\end{array}$} \\
\hline & 0,540 & 0,642 & 0,744 & 0,846 & 0,948 & \\
\hline Peso da carcaça $(\mathrm{kg})$ & 89,38 & 89,61 & 88,39 & 88,66 & 89,46 & 3,42 \\
\hline Espessura de toucinho $\mathrm{P}_{2}(\mathrm{~mm})^{1}$ & 15,43 & 16,41 & 15,31 & 14,11 & 14,48 & 15,94 \\
\hline Deposição diária de carne $(\mathrm{g})^{2}$ & 433,85 & 492,93 & 515,11 & 540,84 & 548,88 & 17,53 \\
\hline
\end{tabular}

${ }^{1}$ Efeito linear $(\mathrm{P}<0,05)$.

2 Efeito linear $(\mathrm{P}<0,01)$.

peso da carcaça com aumento dos níveis de lisina digestível nas dietas.

Os níveis de lisina digestível influenciaram $(\mathrm{P}<0,05)$ a quantidade de carne na carcaça, que aumentou de forma linear, segundo a equação v $=47,7008+3,8363 X\left(r^{2}=0,98\right)$. Lougmiller et al. (1998) e Cline et al. (2000), em pesquisa com fêmeas na fase de terminação, respectivamente, dos 91 aos $113 \mathrm{~kg}$ e dos 54 aos $116 \mathrm{~kg}$, também observaram aumento linear na quantidade de carne com o aumento dos níveis de lisina da dieta. Por outro lado, Souza Filho et al. (2000), Arouca et al. (2004) e Oliveira et al. (2003b) não observaram efeito dos níveis de lisina da dieta sobre a quantidade de carne na carcaça de suínos machos castrados em fase de terminação tardia, dos 90 aos 125 kg.

A espessura de toucinho no ponto $\mathrm{P}_{2}$ apresentou redução linear $(\mathrm{P}<0,05)$, representada pela equação $\hat{Y}=18,5093$ $4,4761 X\left(r^{2}=0,63\right)$, com o aumento dos níveis de lisina digestível na ração. Resultado semelhante foi obtido por Cline et al. (2000), em fêmeas suínas dos 54 aos 116 kg, que apresentaram redução linear da espessura de toucinho no ponto $\mathrm{P}_{2}$ com o aumento do nível de lisina das dietas.

De modo contrário, diversos autores (Friesen et al., 1994b; Hanh et al., 1995; Loughmiller et al., 1998; Souza Filho et al., 2000; Moreira et al., 2002; Oliveira et al., 2003a,b; Arouca et al., 2004, 2005), em pesquisas com suínos machos e fêmeas na fase de terminação tardia, dos 90 aos 125 kg, não observaram efeito dos níveis de lisina sobre a espessura de toucinho no ponto $\mathrm{P}_{2}$. Essa variação entre os resultados pode ser explicada, em parte, pelo potencial genético para deposição de carne na carcaça e pelo sexo dos animais.

Foi observado efeito $(\mathrm{P}<0,01)$ dos níveis de lisina digestível sobre a deposição diária de carne, que aumentou de forma linear, segundo a equação: $\hat{Y}=311,3210+263,7510 X$ $\left(r^{2}=0,87\right)$. Apesar da variação linear na deposição diária de carne, o modelo Linear Response Plateau - LRP (Figura 1) foi o que melhor se ajustou aos dados, e estimou em $0,803 \%$ o nível de lisina digestível a partir do qual ocorreu o platô. Neste nível, obteve-se consumo de lisina digestível correspondente a 24,60 g/dia. Efeito positivo dos níveis de lisina digestível sobre a deposição diária de carne também foi observado por Hahn et al. (1995) em pesquisa com suínos na fase de terminação, dos 90 aos $110 \mathrm{~kg}$.

De forma contrária aos resultados obtidos neste trabalho, Gonçalves et al. (1999) avaliando os efeitos dos níveis de lisina, de energia e sexo dos animais sobre as características de carcaça de suínos híbridos dos 30 aos $112 \mathrm{~kg}$, não observaram efeito dos níveis de lisina das dietas sobre a taxa de crescimento do músculo. De forma semelhante, Arouca et al. (2005), em experimento com suínos machos castrados selecionados geneticamente para alta eficiência de crescimento, dos 96 aos 120 kg, não observaram efeito dos níveis de lisina total sobre a deposição diária de carne.

O melhor valor de deposição diária de carne (544,76 g/dia) obtido neste trabalho pelo modelo LRP foi superior aos observados por Hahn et al. (1995), Gonçalves et al. (1999), Cline et al. (2000), Arouca et al. (2004; 2005), de 342; 415; 315; 470 e 474 g/dia, respectivamente. Essas diferenças podem ser explicadas pelos níveis de lisina e pela genética dos animais utilizados nos trabalhos, uma vez que as linhagens atuais exigem maior quantidade de lisina digestível, em g/dia, para expressar o seu potencial de deposição diária de carne.

\section{Conclusões}

O nível de lisina digestível de $0,803 \%$, que corresponde a consumo de 24,60 g/dia de lisina digestível, proporciona os melhores resultados de ganho de peso e deposição de carne, enquanto o nível de $0,817 \%$, correspondente a consumo de 25,03 g/dia de lisina, proporciona melhor conversão alimentar e o de $0,948 \%$, correspondente a consumo de 29,09 g/dia de lisina digestível, promove maior deposição de carne e espessura de toucinho em suínos machos castrados na fase dos 95 aos $125 \mathrm{~kg}$.

\section{Referências}

ASSOCIAÇÃO BRASILEIRA DE CRIADORES DE SUÍNOS - ABCS. 1973. Método brasileiro de classificação de carcaça. Estrela, RS. $17 p$. 
AROUCA, C.L.C.; FONTES, D.O.; FERREIRA, W.M. et al. Exigências de lisina, com base no conceito de proteína ideal, para suínos machos castrados, de 95 a $122 \mathrm{~kg}$, selecionados para deposição de carne magra. Arquivo Brasileiro de Medicina Veterinária e Zootecnia, v.56, p.773-781, 2004.

AROUCA, C.L.C.; FONTES, D.O.; VELOSO, J.A.F. et al. Exigências de lisina, com base no conceito de proteína ideal, para suínos machos castrados, dos 96 aos 120 kg, selecionados para eficiência de crescimento. Arquivo Brasileiro de Medicina Veterinária e Zootecnia, v.57, p.104-111, 2005.

BERTOL, T.M.; LUDKE, J.V.; FRAIHA, M. et al. Determinação das exigências de lisina digestível para suínos machos castrados e fêmeas dos 80 aos $120 \mathrm{~kg}$ de peso vivo. In: REUNIÃO ANUAL DA SOCIEDADE BRASILEIRA DE ZOOTECNIA, 37., 2000, Viçosa, MG. Anais... Viçosa, MG: SBZ, 2000. p.269 (CD-ROM).

CLINE, T.R.; CROMWELL, G.L.; CRENSHAW, T.D. et al. Further assessment of the dietary lysine requirement of finishing gilts. Journal of Animal Science, v.78, p.987-992, 2000.

DE LA LLATA, M.; DRITZ, S.S.; TOKACH, M.D. et al. Effects of increasing L-Lysine $\mathrm{HCl}$ in corn- or sorghum-soybean mealbased diets on growth performance and carcass characteristics of growing-finishing pigs. Journal of Animal Science, v.80, p.2420-2432, 2002.

D'MELLO, J.P.F. Amino acid supplementation of cereal-based diets for non-ruminants. Animal Feed Science and Technology, v.45, n.1, p.1-18, 1993.

DOURMAD, J.Y.; GUILLOU, D.; SÈVE, B. et al. Response to dietary lysine supply during the finishing period in pigs. Livestock Production Science, v.45, p.179-186, 1996.

EDMONDS, M.S.; BAKER, D.H. Amino acid excesses for young pigs: effects of methionine, tryptophan, threonine or leucine. Journal of Animal Science, v.64, n.6, p.1664-1671, 1987.

FACCIN, M. Tendências da suinocultura brasileira. In: CONGRESSO BRASILEIRO DE VETERINÁRIOS ESPECIALISTAS EM SUÍNOS, 8., 1997, Foz do Iguaçu. Anais... Foz do Iguaçu: ABRAVES, 1997. p.57-69.

FOWLER, V.R.; BICHARD, M.; PEASE, A. Objectives in pig breeding. Animal Production, v.23, p.365-387, 1976.

FRIESEN, K.G.; NELSSEN, J.L.; GOODBAND, R.D. et al. Influence of dietary lysine on growth and carcass composition of high-leangrowth gilts fed from 34 to 72 kilograms. Journal of Animal Science, v.72, p.1761-1770, 1994a.

FRIESEN, K.G.; NELSSEN, J.L.; UNRUH, R.D. et al. Effects of the interrelationship between genotype, sex, and dietary lysine on growth performance and carcass composition in finishing pigs fed to either 104 or 127 kilograms. Journal of Animal Science, v.72, p.946-954, 1994b.

FRIESEN, K.G.; NELSSEN, J.L.; GOODBAND, R.D. et al. The effect of dietary lysine on growth, carcass composition, and lipid metabolism in high-lean growth gilts fed from 72 to 136 kilograms. Journal of Animal Science, v.73, p.3392-3401, 1995.

GONÇALVES, T.M.; BERTECHINI, A.G.; DE KONING, G. et al. Lisina, energia, sexo e períodos experimentais em características de carcaça de suínos híbridos. In: CONGRESSO BRASILEIRO DE VETERINÁRIOS ESPECIALISTAS EM SUÍNOS, Belo Horizonte. Anais... Belo Horizonte: ABRAVES, 1999. p.453-455.

HAHN, J.D.; BIEHL, R.R.; BAKER, D.H. Ideal digestible lysine level for early- and late-finishing swine. Journal of Animal Science, v.73, p.773-784, 1995.

HENRY, Y. Dietary factors involved in feed intake regulation in growing pigs: a review. Livestock Production Science, v.12, n.4, p.339-354, 1985.

JOHNSTON, M.E.; NELSSEN, J.L.; GOODBAND, R.D. et al. The effects of porcine somatotropin and dietary lysine on growth performance and carcass characteristics of finishing swine fed to 105 or 127 kilograms. Journal of Animal Science, v.71, p.2986-2995, 1993.
KILL, J.L.; DONZELE, J.L.; OLIVEIRA, R.F.M. et al. Planos de nutrição para leitoas de alto potencial genético para deposição de carne magra dos 65 aos $105 \mathrm{~kg}$. Revista Brasileira de Zootecnia, v.32, p.1330-1338, 2003.

KING, R.H.; CAMPBELL, R.G.; SMITS, R.J. et al. Interrelationships between dietary lysine, sex, and porcine somatotropina administration on growth performance and protein deposition in pigs between 80 and $120 \mathrm{~kg}$ live weight. Journal of Animal Science, v.78, p.2639-2651, 2000.

LEAL, P.M.; NÃ̃̃S I.A. Ambiência animal. In: CORTEZ, L.A.B.; MAGALHÃES, P.S.G. (Orgs.). Introdução à engenharia agrícola. Campinas: Unicamp, 1992. p.121-135.

LOUGHMILLER, J.A.; NELSSEN, J.L.; GOODBAND, R.D. et al. Influence of dietary lysine on growth performance and carcass characteristics of late-finishing gilts. Journal of Animal Science, v.76, p.1075-1080, 1998.

MOREIRA, I.; GASPAROTTO, L.F.; FURLAN, A.C. et al. Exigência de lisina para machos castrados de dois grupos genéticos de suínos na fase de terminação, com base no conceito de proteína ideal. Revista Brasileira de Zootecnia, v.31, p.96-103, 2002.

NATIONAL RESEARCH COUNCIL - NRC. Nutrient requirements of swine. 10.ed. Washington, D.C.: National Academy Science, 1998. 189p.

OLIVEIRA, A.L.S.; DONZELE, J.L.; OLIVEIRA, R.F.M. et al Lisina para suínos machos castrados de alto potencial genético para deposição de carne magra dos 95 aos $110 \mathrm{~kg}$. Revista Brasileira de Zootecnia, v.32, p.337-343 2003a.

OLIVEIRA, A.L.S.; DONZELE, J.L.; OLIVEIRA, R.F.M. et al. Lisina em rações para suínos machos selecionados para deposição de carne magra na carcaça dos 110 aos $125 \mathrm{~kg}$. Revista Brasileira de Zootecnia, v.32, p.150-155 2003b.

QUINIOU, N.; DUBOIS, S.; NOBLET, J. Voluntary feed intake and feeding behaviour of group-haused growing pigs are affected by ambient temperature and body weight. Livestock and Production Science, v.41, p.245-253, 2000.

ROSTAGNO, H.S.; ALBINO, L.F.T.; DONZELE, J.L. et al. Tabelas brasileiras para aves e suínos: composição de alimentos e exigências nutricionais de aves e suínos. Viçosa, MG: UFV, Imprensa Universitária, 2000. 141p.

ROSTAGNO, H.S.; ALBINO, L.F.T.; DONZELE, J.L. et al Tabelas brasileiras para aves e suínos: composição de alimentos e exigências nutricionais. 2.ed. Viçosa, MG: UFV, Imprensa Universitária, 2005. 186p.

ROSSONI, M.C.; DONZELE, J.L.; OLIVEIRA, R.F.M. et al Níveis de treonina digestível para suínos machos castrados, de alto potencial genético para deposição de carne, na fase de terminação. Arquivo Brasileiro de Medicina Veterinária e Zootecnia, v.60, p.884-889, 2008.

SOUZA FILHO, G.A.; LIMA, J.A.F.; FIALHO, E.T. et al. Efeito de planos de nutrição e de genótipos sobre características físicas de carcaça de suínos. Ciência Agrotécnica, v.24, p.1060-1067, 2000 .

STAHLY, T.S.; CROMWELL, G.L.; TERHUNE, D. Responses of high, medium and low lean growth genotypes to dietary amino acid regimen. Journal of Animal Science, v.69, suppl. 1, p.364, 1991. (Abstr.).

STAHLY, T. Nutrition effects lean growth, carcass composition. Feedstuffs, v.65, p.12, 1993

UNIVERSIDADE FEDERAL DE VIÇOSA - UFV. S.A.E.G. (Sistemas de Análises Estatísticas e Genéticas). Viçosa, MG: 2000. (Versão 8.0).

WITTE, D.P.; ELLIS, M.; McKEITH, F.K. et al. Effect of dietary lysine and environmental temperature during the finishing phase on the intramuscular fat content of pork. Journal of Animal Science, v.78, p.1272-1276, 2000 